\title{
A Research into the Roles of College English Teachers as Subject and Object: a Perspective of Educational Linguistics
}

\author{
Tuanhua Lu \\ Xianyang Normal University Foreign Languages Institute, Xianyang, Shaanxi, China 712000
}

\begin{abstract}
Keyword: Educational linguistics; College english teachers; Roles; Path
\end{abstract}
\begin{abstract}
Educational linguistics sets college English teachers at the core of higher English education, and grants them roles as the subject of English discipline and the object of academic research. Both roles should be defined in the specific educational settings. To seek further achievements, college English teachers must play both roles well. They should effectively fulfill their roles into the background of their educational culture by pinpointing the relation between beliefs and actions, language and education, discipline and talents. Only in this way can college English teachers actualize their dual roles.

There are three problems with the current researches into college English teachers. First, there is no special theory for the development of college English teachers which is mostly supported by theories of other disciplines. Second, the development of college English teachers has not been studied as an independent secondary subject of pedagogy, nor has it highlighted the characteristics of education and development of college English teachers. Third, in terms of the specific study, there is lack of research into the mechanism of the teachers' development and their roles. The main reason for the above problems lies in the fact that there is no specific discipline engaged in their development.
\end{abstract}

\section{Roles of College English Teachers Viewed from Education Linguistics}

"Educational Linguistics" is originated from both pedagogy and linguistics. Fundamentally, the essence of its research is human development. Therefore, it is a human-centered (mainly educated-based) discipline, which essentially studies the development of language educators. From the perspective of Educational Linguistics, college English teachers assume a dual role in that they are not only the subject of development, but also the object of development. The focus of educational linguistics shows that college English teachers are not only the researchers and implementers of policies, theories and practices of foreign language education, but also act as the subject and the object of academic researches.

The Subject and Object of Language Education Researches. In educational researches, college English teachers play the dual role of the subject and the object. Modern applied linguistics studies language teaching with linguistic theories. It is believed that college English teachers must have a comprehensive understanding of teaching methodology and neglect the human factors in teaching. Educational Linguistics starts with educational practices and holds that college English teachers are both the ones to research and to be researched.

Corson points that the main line for educators to understand and research language teaching is the environmental mechanism and the role of college English teacher. Hult, F. and Spolsky shift their researches from pedagogy to the role of college English teachers. The fact that college English teachers are taken as the focus clearly shows their value as the research object. At the same time, the studies of teachers' cognition, teachers' beliefs and the cultural mechanism of teachers' development have become the new fields of college English teachers. Besides, the thinking and behavior of college English teachers have become the main object of educational research, which are beyond the scope of linguistics and teaching methodology.

The Subject and Object of Language Education Policies. Language policies include macroscopic and microscopic language policies and teachers' education policies as well. Macroscopic language policies mainly refer to the national language policy, and micro language policies are mainly targeted at actual classroom teaching practices. Educational policies mainly relate to the norms and measures to promote the growth of college English teachers. Educational policies can be formulated either by the state or by each college. College English teachers, by observing national policies, can make micro teaching 
policies, such as classroom rules. College English teachers are the main makers of micro policies, and sometimes they expand or alter macroscopic education policies and theories so as to play a dominant role.

College English teachers are also the object of language policies. Educational policies contain enormously, and teachers' education has become an indispensable part of them. The development policies of college English teachers in China cover three stages: training, educating, and developing. Teachers' training has extended from the knowledge and theories of a discipline to educational theories, psychological theories and English language learning theories. As the research object, college English teachers are different from those of other disciplines, and their teaching is more obviously influenced by human factors. In view of this, researches into the object role of college English teachers should focus on their role as human beings in specific mechanisms.

The Principles to Define the Roles Played by College English Teachers. College English teachers are not only the main undertakers of the researches into college English teachers' development, but also the main object. Therefore, the defining of the roles of college English teachers should be guided by Educational Linguistics and focus on college English teachers in specific educational culture. It is not those top-down authoritative theories that influence the roles of college English teachers but the specific bottom-up educational culture. These top-down educational and cultural mechanisms have a major impact on their cognitive development, the choice of teaching strategies, the selection of teaching methods, the decision of teaching contents and even the teaching language. Therefore, the definition of their roles should not be confined to the framework of linguistics, but be based on a specific bottom-up educational and cultural mechanism.

\section{The Current Situation of the Role of College English Teachers}

When applied to different disciplines, a mechanism will show up differently. In education, a mechanism emerges as an educational one. The educational mechanism mainly includes the components and the operation of educational activities. In general, the operation of an educational mechanism mainly concerns three aspects: the formal, the level, and the functional, which constitute the cultural environment of Educational Linguistics. In practice, these cultural mechanisms in education mainly include the teaching, evaluating and training of college English teacher.

The Current Education of College English Teachers. At present, teachers' education in China does not pay enough attention to teachers' actual needs and their roles. College English teachers mainly are graduates of English majors of normal universities, foreign studies universities and comprehensive universities. However, no matter which university, they share similarities in terms of course setting and class schedules. For example, English majors in all colleges and universities all adopt the uniform standard of English education and all the English majors should take the TEM4. In the meantime, most colleges and universities aim at cultivating "compound talents", which requires that college English teachers must obtain kinds of knowledge. Therefore, to work out the mode and pattern to education the teachers, we must pay more and more attention to the conflict between the ideal role of college English teacher and the realistic education mechanisms, which will highlights the value of Educational Linguistics.

The Current Evaluation of College English Teachers. The teachers' competence not only includes the ability to impart language knowledge and promote students' language skills, but also the ability to handle classroom teaching and the ability to solve practical problems at a macro level in various language teaching activities. Therefore, the teachers should posses such comprehensive competence. The progress of such competence is affected by various factors as education, management and evaluation mechanisms.

At present, the evaluation of our college English teachers mostly is conducted in such aspects as teaching knowledge, teaching skills, academic researches, professional quality and student evaluation and so on. In the aspect of teaching ability evaluation, it is generally recognized that the teachers should be evaluated before the class, during the class and after the class. Their ability structure is an important part of the ability system of college English teachers, which is both dynamic and static. Therefore, the evaluation of college English teachers' ability needs to be comprehensively planned and evaluated from multiple perspectives, considering particular disciplines, the specific education environment and the 
unique roles of college English teachers. A scientific evaluation system of college English teachers must fully reflect the specialty of the language discipline, the requirements for their roles and the local culture. It is an evaluation system that can promote their growth and development.

\section{The Path to Actualize College English Teachers' Dual Roles}

Educational Linguistics studies the relationships between various organizations, between individuals, and even between organizations and individuals. Educational linguistics researches the roles of college English teachers as both the subject and the object. It further shows that college English teachers are the main practitioners to effectively meditate various relations. College English teachers combine their various experiences in teaching so as to integrate their practical roles with related mechanisms and then promote human development through language education.

The Role as the Subject. Speaking for the main role of college English teachers, they should focus on themselves and combine their own intrinsic beliefs with external practices. The combination is one of the most important and effective ways for college English teachers to conform to their roles and mechanisms and achieve their own development. Researches into beliefs and behaviors of college English teachers are still at the infancy stage in China, and these studies hold that theory closely guides their behaviors. Related surveys find a giant disconnection between their beliefs and practices. The main reason is that the ideal role that College English teachers are keen on is not effectively integrated into actual mechanisms. The current educational mechanisms play an important role in guiding their teaching. To narrow the gap between their beliefs and behaviors and to achieve the effective combination of the two, we must tie their roles to the educational mechanisms. The construction of the development mechanism for college English teachers cannot blindly follow western theories and convictions. Education should be based on "native culture", which can be either Chinese national culture or regional culture. In the end, it will form a implementing mechanism that can meet the practical and development requirements of college English teachers, so as to promote the scientific and effective combination of their beliefs and behaviors.

The Role as the Object. Combining Language with Education

The object role should be based on the interdisciplinary features of Educational Linguistics, and combine language and education. Educational Linguistics consists of two parts: education and language. Educational Linguistics is no longer just teaching of linguistic knowledge, but rather a study of the correlation between English education and English linguistics, or the significance of one's development for the other. College English teachers bridge the process. Their knowledge structure includes six aspects: teaching theories, teaching skills, discipline knowledge, communicative competence, teaching reasoning and environmental judgment. Among them, communicative competence, teaching reasoning and environmental judgment fully show educational elements in the development of college English teachers. Teaching skills and classroom skills fully indicate the overall requirements for college English teachers in the sense of language ability and teaching competence. At the same time, the development of college English teachers generally needs to go through three different stages: professional practice, reflection and career development. Each stage has different development priorities.

Combining the Discipline with Talent Cultivation

By combining the discipline with educational policies, Educational Linguistics provides multi-channel and diversified information for educational policies. However, the integration of foreign language as a discipline and its teaching must stem from the effective joining of college English teachers in Educational Linguistics. On the surface, Educational Linguistics studies language teaching. However, to a deeper level, it actually researches the inner thoughts and external behaviors of college English teachers. It aims at language-based teaching theories by taking language teaching practice as a path. At present, to enhance their development, especially their professionals, teaching theories are regarded as one of the important ways. However, we must give full consideration to the educational and cultural mechanisms. At the same time, Educational Linguistic would not be an independent science without the dual roles of college English teachers as the subject and the object. In view of this, the development of college English teachers must be closely integrated into the current education. We must position the appropriate breakthrough point of college English teachers' roles and educational mechanisms by taking Educational 
Linguistics as the paradigm and combining the discipline with talents cultivation, which is expected to promote the development of college English teachers.

\section{Acknowledgements}

【Fund Source】 1. This paper is funded by the Project of Talents of Xianyang Normal University (No.: XSYQL201510). 2. This paper is funded by the 13th Five-Year Plan Fund of Educational Scientific Research of Shaanxi Province (No.: SGH17H179).

\section{Reference}

[1] M. Yan. The Combination of Role and Mechanism: The Development of Teachers in the Field of Educational Linguistics [J]. Foreign Language and Foreign Languages Teaching, 2016 (03).

[2] Y. Q. Wu. and others. Objective Alienation and Subjective Regression of Teacher Development [J]. Educational Research, 2013 (01).

[3] L. P. Xiao. Review of Research on Teacher Professional Development at Home and Abroad [J]. Chinese Journal of Education, 2002 (5).

[4] Y. Zhou. Tactics to Promote Teacher's Tacit Knowledge Sharing [D]. Qufu: Qufu Normal University, 2007.

[5] J. H. Zhang. Research on the Development of American University Teachers [J]. Higher Education Exploration, 2010 (02): 45-48.

[6] H. J. Lai. Current Situation and Problems of Teacher Education and Development in China [J]. Education and Teaching Research, 2009 (05).

[7] Y. X. He. Thinking and Practice of Evaluation System of College English Teachers from the Perspective of Development of University Teachers [J]. Higher Engineering Education Research, $2016(01)$.

[8] J. Liu. Study on the Development Mechanism of Teachers' Teaching Ability in Local Colleges and Universities [J]. Higher Education Research in Hei Longjiang, 2017 (02).

[9] J. M. Xia. A Summary of Foreign Language Teachers' Development [J]. Foreign Language in China, $2006(01)$.

[10] S. R. Wang. How to Promote the Development of College Foreign Language Teachers [J]. Theory and Practice of Foreign Language Teaching, 2017 (05).

[11]X. H. Jiang. Research on the Self-development of Foreign Language Teachers in Higher Education Institutions in the Background of Teacher Professional Development [J]. Hei Longjiang Higher Education Research, 2013 (03).

[12] S. H. Han. New Orientation of Foreign Language Teacher Development from the Perspective of Social Cognitivism [J]. Foreign Language Education Research, 2013 (11). 